\title{
A review of epigenetic and gene expression alterations associated with intracranial meningiomas
}

\author{
Shuhan He, B.S., ${ }^{1}$ Martin H. Pham, M.D., ${ }^{1}$ Matthew Pease, B.S., ${ }^{1}$ Gabriel Zada, M.D., ${ }^{1}$ \\ Steven L. Giannotta, M.D., ${ }^{1}$ Kai Wang, PH.D., ${ }^{2,3}$ and William J. Mack, M.D. ${ }^{1,3}$ \\ Departments of ${ }^{1}$ Neurosurgery and ${ }^{2}$ Preventive Medicine, and ${ }^{3}$ Zilkha Neurogenetic Institute, Keck School of \\ Medicine, University of Southern California, Los Angeles, California
}

\begin{abstract}
Object. A more comprehensive understanding of the epigenetic abnormalities associated with meningioma tumorigenesis, growth, and invasion may provide useful targets for molecular classification and development of targeted therapies for meningiomas.

Methods. The authors performed a review of the current literature to identify the epigenetic modifications associated with the formation and/or progression of meningiomas.

Results. Several epigenomic alterations, mainly pertaining to DNA methylation, have been associated with meningiomas. Hypermethylation of TIMP3 inactivates its tumor suppression activity while CDKN2 (p14[ARF]) and TP73 gene hypermethylation and HIST1H1c upregulation interact with the p53 regulation of cell cycle control. Other factors such as HOX, IGF, WNK2, and TGF- $\beta$ epigenetic modifications allow either upregulation or downregulation of critical pathways for meningioma development, progression, and recurrence.

Conclusions. Genome-wide methylation profiling demonstrated that global hypomethylation correlates with tumor grades and severity. Identification of additional epigenetic changes, such as histone modification and higherorder chromosomal structure, may allow for a more thorough understanding of tumorigenesis and enable future individualized treatment strategies for meningiomas.
\end{abstract}

(http://thejns.org/doi/abs/10.3171/2013.10.FOCUS13360)

KEY WORDS
genomics

M ENINGIOMAS, which originate from the arachnoidal cap cells of the leptomeninges,$^{50}$ have an incidence of 4.4 per 100,000 person-years ${ }^{74}$ and are the most commonly diagnosed primary brain tumor. ${ }^{22}$ The peak incidence of meningiomas occurs in the 6th and 7th decades, and women are affected nearly twice as often as men. ${ }^{48}$

Meningiomas are often organized with the WHO classification of tumors, with $80 \%$ being considered Grade I (benign); $10 \%-15 \%$, Grade II (atypical); and $2 \%-5 \%$, Grade III (anaplastic/malignant). ${ }^{9}$ Grade III meningiomas are typically associated with brain invasion and recurrence, and the overall 10-year survival rate for patients with these lesions is only $14.2 \% .^{22}$ Thus, it is of critical clinical significance to accurately determine the characteristics of these tumors in a timely fashion. The WHO pathological grading system cannot always accurately predict the clinical aggressiveness of these tumors, and grading is subject

Abbreviations used in this paper: $\mathrm{MMP}=$ matrix metalloproteinase; p53 = tumor suppressor p53 (cellular tumor antigen p53); uPA $=$ urokinase plasminogen activator. to sampling error and inter-user variability. ${ }^{38}$ Additional possible explanations for the difficulty in predicting the behavior of meningiomas have included the observations that there are numerous histological similarities between tumors in each grade and that these tumors exist along a spectrum in which low-grade meningiomas can progress to a higher grade. ${ }^{2}$ There is no clear explanation, however, as to why the majority of recurrent meningiomas derive from benign histology even after apparently radical removal. ${ }^{55}$

Other attempts to classify meningiomas have used genomic techniques to study their genesis and progression, ${ }^{73}$ as well as to search for genetic mutations and variable gene expression mediated via epigenetic modifications..$^{35}$ The use of epigenomics as a clinical tool has become better understood in recent years ${ }^{47}$ and research has started to elucidate the importance of epigenetics in meningioma progression. Data suggest that there is an absence of any significant genetic alterations in nearly $40 \%$ of meningiomas. ${ }^{31,52}$ One study found that $77 \%$ of meningiomas had at least 1 methylated gene, and 25\% of samples in another study had 3 or more methylated genes. ${ }^{5}$ Epigenetic alterations in the genome are also par- 
ticularly useful to examine because they are thought to occur in the early stages of tumorigenesis ${ }^{35}$ and can function through multiple mechanisms to cause runaway cell growth (Fig. 1).

In this review, we present a systematic analysis of the genes that are known to undergo epigenetic modifications as related to the development, progression, and recurrence of intracranial meningiomas. This article summarizes the literature pertaining to the epigenetic modification of meningiomas and provides a brief discussion for future avenues of molecular classification, prognosis, and epigenetic therapies (epidrugs), that could provide significant clinical value to patients with meningiomas in the future.

\section{Methods}

A systematic review of the PubMed database was performed to identify all studies published up to $\mathrm{Au}$ gust 2012, using all combinations of the search terms "meningioma," "epigenetics," "methylation," "histone," "sequencing," and "acetylation." Only English-language publications were included in our query. Two investigators independently screened all identified abstracts for potential inclusion. To be considered eligible for inclusion, a study looked at the epigenetic changes to meningiomas defined as alterations in levels of gene expression that are not accompanied by changes in the primary DNA sequence. ${ }^{35}$

\section{Results}

A primary and secondary review of all identified abstracts resulted in 138 studies that met initial inclusion criteria. Of these studies, 112 were discarded due to 1) identified changes in the underlying DNA sequence or 2) publication in a language other than English. The resulting 26 studies from the systematic search were then classified according to gene subtype affected by epigenetic modification.

\section{Tumor Suppressor Genes}

The best understood of the tumor suppressor genes as pertaining to epigenetic regulation of meningiomas is the TIMP3 (TIMP metallopeptidase inhibitor 3 or tissue inhibitor of metalloproteinase 3), which encodes for a protein that inhibits matrix metalloproteinases (MMPs) (Table 1). A second function appears to be a unique tumor suppressor-like property that is not related to MMP inhibition. ${ }^{3}$ Overexpression of TIMP3 in vitro has been shown to suppress tumor growth and induce apoptosis. ${ }^{7}$ Hypermethylation of the 22q12 gene TIMP3 and subsequent transcriptional downregulation (gene silencing) has been identified as a marker for an aggressive, high-grade meningioma phenotype. ${ }^{4,49}$ Although there is some minor disagreement in the literature, Grade I tumors have been found to have significantly less aberrant methylation at TIMP3 than Grade II or III meningiomas. ${ }^{5}$

The urokinase plasminogen activator (uPA) system functions via extracellular matrix proteolysis to facilitate cellular adhesion and migration. ${ }^{51}$ Active uPA activates plasminogen to plasmin, which degrades the extracellular matrix and activates various MMPs, ${ }^{1}$ intersecting with the pathway of TIMP-3. Increased expression of uPA proteins is associated with higher WHO grade, malignant invasion, and recurrence. ${ }^{40,85}$

TP53. Tumor suppressor p53 (cellular tumor antigen p53, p53) is a ubiquitous component in growth regulation that interacts with multiple other pathways to control the cell cycle. Loss of chromosome 9 is of particular impor-

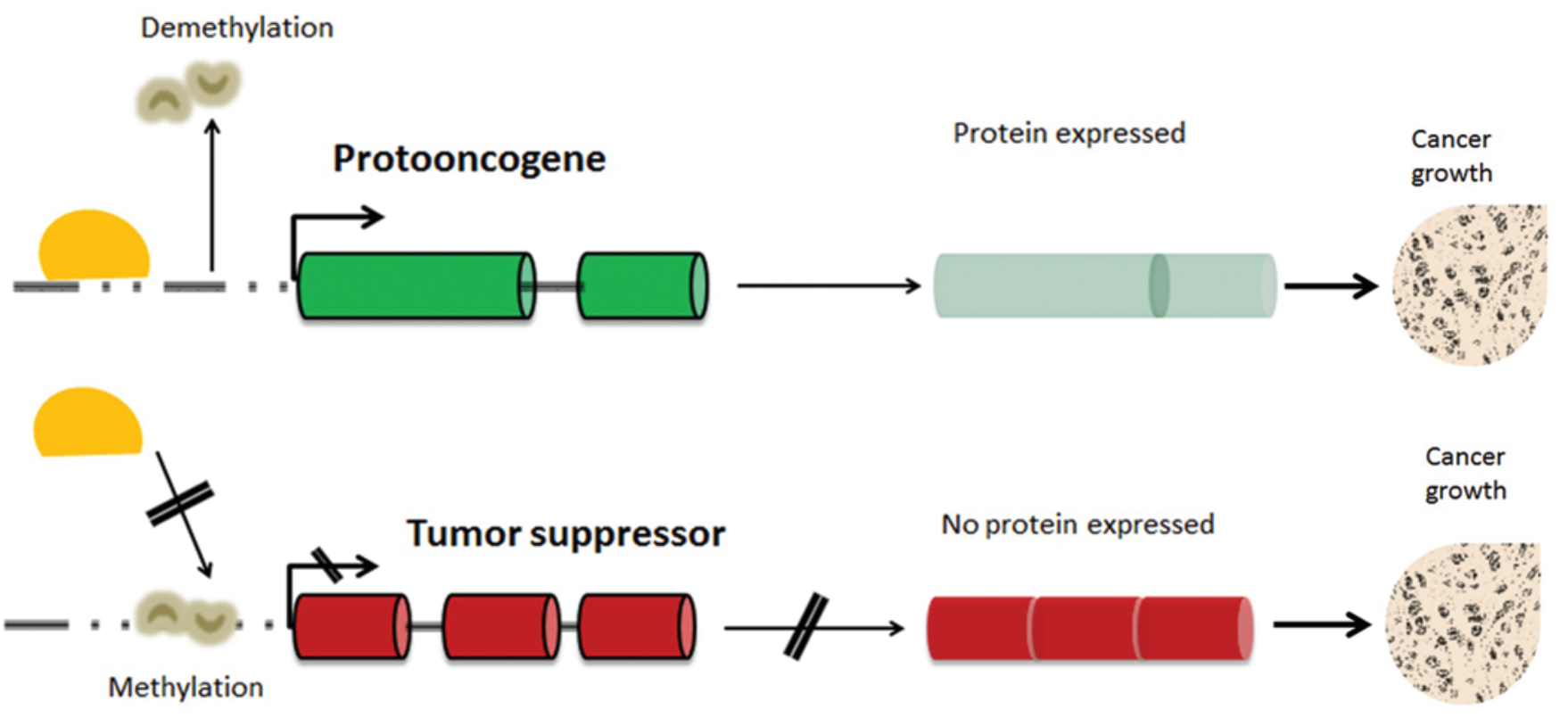

FIG. 1. Two possible mechanisms for oncogenesis via epigenetic modifications. Upper: A proto-oncogene is demethylated, allowing for transcription factors to bind and express the oncogenic product, allowing runaway cellular growth. Lower: A normally unmethylated tumor suppressor gene becomes methylated through epigenetic modifications, inhibiting transcription and thus leading to proliferation of meningioma through loss of function. 
Epigenetic and gene expression alterations in meningioma

TABLE 1: Tumor suppressor genes

\begin{tabular}{llllll}
\hline \multicolumn{1}{c}{ Gene } & Locus & \multicolumn{1}{c}{ Product } & Modification & Function & \multicolumn{1}{c}{ Effect } \\
\hline TIMP3 & $22 \mathrm{q} 12.3$ & metalloproteinase inhibitor 3 & hypermethylation & MMP inhibition & higher meningioma grade $^{14,15}$ \\
CDKN2A (p14[ARF]) & $9 \mathrm{p} 21.3$ & P14ARF protein & hypermethylation & cell cycle control & tumorigenesis $^{1}$ \\
TP73 & $1 \mathrm{p} 36$ & P73 protein & hypermethylation & cell cycle control & tumorigenesis $^{14,22}$ \\
TMEM30B & $14 \mathrm{q}$ & transmembrane factor & hypermethylation & cell cycle & recurrence $^{2}$ \\
HIST1H1C & $6 \mathrm{p} 21.1$ & histone H1.2 & upregulation & cell cycle & recurrence $^{2}$ \\
MEG3 & $14 \mathrm{q} 32$ & noncoding RNA & hypermethylation & cell cycle & tumorigenesis \& grade $^{3}$ \\
\hline
\end{tabular}

tance because of 3 notable tumor suppressor genes located on its short arm. CDK2NA (p14[ARF]) is a gene on the 9p21 locus that interacts with TP53 and regulates the transition from the $\mathrm{G}_{1} / \mathrm{S}$-phase checkpoint. Previous mutational studies of CDK2NA (p14[ARF]) have shown that allelic losses, including homozygous deletions at 9p21, are important components of the progression of atypical and anaplastic meningiomas. ${ }^{8}$ The p14ARF (cyclindependent kinase inhibitor $2 \mathrm{~A}$, isoform 4) protein binds to the MDM2 oncogene (MDM2) and promotes the rapid degradation of the MDM2 regulator protein, preventing the degradation of p53.99 Methylation and inhibition of this pathway consequently increases p53 breakdown and prevents the normal cell cycle checkpoint function. Inactivation of this p14ARF and p53 pathway through hypermethylation has been shown to occur frequently in human brain tumors. ${ }^{97}$

The tumor suppressor protein $\mathrm{p} 73$, which shares significant sequence homology with $\mathrm{p} 53,{ }^{39}$ also plays an important role in malignant meningiomas. ${ }^{14,22}$ Previous research has indicated that p73 has opposing functions of both cell growth and cell cycle arrest. ${ }^{58}$ Epigenetic studies show that p73 plays a similar dual role in meningioma progression. Hypermethylation may cause development of some low-grade forms, whereas enhanced p73 expression characterizes malignant meningiomas. ${ }^{64}$

HIST1H1c. Histone cluster 1, H1c is a gene on chromosome 6 that has been found to be overexpressed in $27 \%$ and $89 \%$ of original and recurrent meningiomas, respectively, in a study by Pérez-Magán et al. ${ }^{69}$ It is hypothesized that the physical interaction of the H1.2 protein can participate in the epigenetic regulation of gene expression by maintaining specific DNA methylation patterns. ${ }^{24}$ More specifically, the authors hypothesize that it may suppress p53-dependent p300-mediated chromatin transcription by blocking chromatin acetylation.

The importance of p53 in preventing meningioma development and grade extends to another gene, MEG3 (maternally expressed 3), an imprinted gene with maternal expression that encodes a noncoding RNA. Previous research showed that MEG3 RNA functions by activating p53 target genes and stimulates p53-mediated transcriptional activation. ${ }^{100}$ Zhang et al. ${ }^{98}$ hypothesized that since $M E G 3$ is located at $14 \mathrm{q} 32$, a region that has been previously associated with meningioma progression, it would be an ideal candidate for epigenetic meningioma progression. Their research showed that MEG3 RNA is highly expressed in normal arachnoidal cells but not expressed in the major- ity of meningiomas, whereas high-grade meningiomas frequently show a higher degree of MEG3 methylation ( $\mathrm{p}=$ 0.038 ) as well. Furthermore, when $M E G 3$ cDNA was tested in vitro on meningioma cell lines, the gene was found to suppress colony formation by $80 \%$, similar to the rate of other known growth suppressors. The study illustrates the importance of epigenetic regulation of p53 as a key inhibitor of meningiomas.

Atypical anaplastic meningiomas show higher expression of the GADD $45 A$ gene $^{94}$ when compared with benign meningiomas, similar to increases previously found in pancreatic carcinomas. ${ }^{96}$ Three additional genes were identified by Wrobel et al. through mRNA expression and immunohistochemistry as having a stronger expression profile in atypical and anaplastic meningiomas than benign meningiomas: PCNA, STK15 (AURKA), and $C E N P F .^{94}$ PCNA interacts with GADD45A (GADD45) and functions as a cofactor for DNA polymerase, causing cell proliferation. ${ }^{56}$ STK 15 encodes aurora kinase A, a centrosome-associated serine/threonine kinase previously shown to be amplified in colon cancer, ${ }^{28}$ while $C E N P F$ encodes mitosin, a protein of centromere-kinetochore complex protein that is involved in cell division of somatic cells and involved in a range of oncogenic pathologies. ${ }^{44,86}$

Other tumor suppressor genes that do not involve the p53 pathway include TMEM3OB and GSTP1. TEME3OB is a gene in the $14 \mathrm{q}$ region that encodes a transmembrane factor that participates in the cell cycle. ${ }^{11}$ It had previously been found to be expressed in meningiomas ${ }^{41}$ and is downregulated in recurrences compared with nononcogenic tissue. ${ }^{17}$ GSTP1 is a member of the glutathione$\mathrm{S}$-transferase family. Its function is to conjugate carcinogens with glutathione, which neutralizes it and allows its excretion, preventing DNA damage. ${ }^{33}$ Hypermethylation of GSTP1 was found with an increasing frequency from $0 \%$ in benign to $32 \%$ in atypical to $54 \%$ in anaplastic variants ${ }^{49}$ of meningiomas in one study by Liu et al., and thus GSTP1 promoter region hypermethylation is associated with meningioma grade. ${ }^{49}$

\section{Cell Signaling}

The homeobox (HOX) family of genes is a target for gene silencing via DNA comethylation ${ }^{21,83}$ and is frequently identified in a wide variety of human tumorigenesis $^{76,90,95}$ (Table 2). The concordant methylation of $H O X A$ genes on 7p15.2, including HOXA5, HOXA6, HOXA9, and $H O X A 11$ leads to the downregulation of tumor suppressor targets. ${ }^{45}$ Kishida et al. $^{45}$ used high-throughput 
S. He et al.

TABLE 2: Cell signaling

\begin{tabular}{|c|c|c|c|c|c|}
\hline Gene & Locus & Product & Modification & Function & Meningioma Effect \\
\hline $\begin{array}{l}\text { HOXA5, HOXA6, } \\
\text { HOXA9, \& HOXA11 }\end{array}$ & $7 \mathrm{p} 15.2$ & $\begin{array}{l}\text { HOXA5, HOXA6, } \\
\text { HOXA9, \& HOXA11 }\end{array}$ & comethylation & transcription factor & tumorigenesis ${ }^{4}$ \\
\hline PENK & $8 q 23$ & preproenkephalin & hypermethylation & apoptosis & tumorigenesis ${ }^{4}$ \\
\hline UPKЗ & $22 q 13.31$ & uroplakin-3a & hypermethylation & growth factor & tumorigenesis ${ }^{4}$ \\
\hline IGFBP3 & 7p13-p12 & $\begin{array}{l}\text { insulin-like growth factor } \\
\text { binding protein } 3\end{array}$ & upregulation & growth factor & cell growth \& tumor aggressiveness ${ }^{5}$ \\
\hline IGF2 & $11 \mathrm{p} 15.5$ & IGF-2 protein & upregulation & growth factor & cell growth \& tumor aggressiveness ${ }^{6}$ \\
\hline IGFBP2 & $2 q 33$ & $\begin{array}{l}\text { insulin-like growth factor } \\
\text { binding protein } 2\end{array}$ & upregulation & growth factor & cell growth \& tumor aggressiveness ${ }^{4}$ \\
\hline IGF2BP1 & $17 q 21.32$ & RNA binding protein & hypermethylation & transcription factor & tumorigenesis ${ }^{4}$ \\
\hline WNK2 & $9 q 22.31$ & WN kinase & hypermethylation & growth factor & tumorigenesis \\
\hline NDRG2 & $14 q 11.2$ & NDRG2 protein & hypermethylation & transcription factor & cell growth \& tumor aggressiveness ${ }^{7}$ \\
\hline LMO4 & $1 \mathrm{p} 22.3$ & $\begin{array}{l}\text { LIM domain transcription } \\
\text { factor LMO4 }\end{array}$ & downregulation & transcription factor & tumorigenesis² \\
\hline CTGF & $6 q 23.2$ & CTGF & hypermethylation & growth factor & recurrence $^{2}$ \\
\hline CTNNB1 & $3 p 21$ & $\beta$-catenin & downregulation & Wnt signaling & cell growth \& tumor aggressiveness 8 \\
\hline CDK5R1 & $17 q 11.2$ & CDK5R1 protein & upregulation & Wnt signaling & cell growth \& tumor aggressiveness ${ }^{5}$ \\
\hline ENC1 & $5 q 12-q 13.3$ & ENC 1 protein & upregulation & Wnt signaling & cell growth \& tumor aggressiveness 5 \\
\hline CCND1 & $11 q 13$ & CCND1 protein & upregulation & Wnt signaling & cell growth \& tumor aggressiveness ${ }^{5}$ \\
\hline$A L P L$ & 1p36.1-p34 & alkaline phosphatase & downregulation & cell cycle control & progress \& grade ${ }^{9}$ \\
\hline THBS1 & $15 q 15$ & thrombospondin 1 & methylation & angiogenesis inhibition & angiogenesis ${ }^{1}$ \\
\hline
\end{tabular}

genome-wide DNA methylation analyses of high-grade and high-recurrence meningiomas, and identified several genes potentially implicated in meningioma progression. These genes included HOXA6 and HOXA9 as identified previously by Di Vinci et al., ${ }^{21}$ along with genes $P E N K$ and $U P K 3 A$.

These candidate genes have been identified as methylation targets in various other tumors. PENK has been identified in other genome-wide analysis of various solid tumors. ${ }^{10,80}$ Although its role in oncogenesis is still relatively unknown, a recent study suggested that cellular stress induces PENK to physically bind with p53 and RELA (p65) to regulate stress-induced apoptosis. ${ }^{57}$ This would seem in concordance with previous evidence that p53-related pathways play an important role in meningioma epigenetically mediated oncogenesis. UPK $3 A$ codes for uroplakin-3a, one of a group of transmembrane proteins that form complexes on the surface of bladder epithelium. ${ }^{102}$ DNA methylation of the promotor region of $U P K 3 A$ is the primary mechanism underlying silencing of the gene, and such alterations have also been reported in metastasis of colorectal neoplasms. ${ }^{36}$

$I G F$. The IGF signaling family and the anomalous expression of IGF, IGF receptor, and IGF-binding proteins have been demonstrated as a key signaling pathway in the tumorigenesis of meningiomas. The literature has consistently revealed that the increased expression of $I G F B P 3$ and $I G F 2$ transcripts, along with decreased expression of $I B F B P 2$, is important in meningioma progression and anaplastic classification. ${ }^{65,92,94}$ It was reported that IGFBP3 may potentiate IGF1 action by altering B/ AKT protein kinase sensitivity to IGF-1 receptor signal- ing. ${ }^{12}$ Furthermore, IGFBP1 is an RNA-binding protein that regulates mRNA stability and translocation. It is hypothesized to play a role in tumorigenesis by stabilizing messenger RNAs of the $c$-myc oncogene and $I G F 2$ in certain cancers. ${ }^{45}$

WNK2. In meningiomas, Jun et al. found that WNK2 was aberrantly methylated in $83 \%$ and $71 \%$ of Grade II and III meningiomas, respectively, but rarely methylated in 13 other tumor types. The authors noted that aberrant methylation of the $\mathrm{CpG}$ island was associated with decreased gene expression in primary tumors, while expression of exogenous WNK2 inhibited colony formation, implicating it as a potential cell growth suppressor. ${ }^{37,71}$ WNK2 has been shown to inhibit cell proliferation in vitro by negatively modulating the activation of MEK1/ ERK1/2 and epidermal growth factor receptor (EGFR) signaling. EGFR is thought to be an important oncogene in meningiomas, and WNK2 silencing could potentially enhance EGFR protein signaling. ${ }^{60}$ Jun et al. showed that WNK2 could be reactivated with a methylation inhibitor in IOMM-Lee cells, and thus their findings may be translatable to the bedside.

NDRG2. N-myc downstream regulated gene 2 $(N D R G 2)$ is normally expressed in brain, heart, and muscle and is one of 4 members of the NDRG family. ${ }^{75}$ It has been implicated in cell growth as well as apoptosis, and identified by Lusis et al. as a gene that is consistently downregulated in Grade III meningioma and independent sets of diverse meningiomas. The loss of NDRG2 expression was significantly associated with hypermethylation of the $N D R G 2$ promoter. ${ }^{54}$ 


\section{Epigenetic and gene expression alterations in meningioma}

TGF- $\beta$. The gene LMO4 (1p22.3) is a novel candidate in meningioma epigenetic research. It is silenced more often in original meningiomas (32\%) than in normal meningothelial tissue, although in recurrences of meningiomas the expression is similar. ${ }^{69}$

LMO4 has previously been identified as a gene that is overexpressed in breast ${ }^{15,61,101}$ and pancreatic tumors ${ }^{63}$ and is known to function in mesenchymal cell-epithelial cell interactions. The authors of the meningioma study suggest that LMO4 modulates TGF- $\beta$ signaling through its interaction with receptor-activated SMADs, supporting the finding of the downregulation of the TGF- $\beta$ pathway in recurrent meningiomas. ${ }^{53}$

Involvement of the TGF- $\beta-$ SMAD pathway seems to also include the $C T G F$ gene, ${ }^{11}$ whose product is a growth factor secreted by vascular endothelial cells and has various regulatory functions in cell growth and apoptosis. $C T G F$ has been found to have significantly lower expression in recurrent meningiomas than in original meningiomas in microarray expression data $(\mathrm{p}<0.05){ }^{69}$

Notch. The Notch pathway is another signaling cascade that has been implicated in tumorigenesis through epigenetic mechanisms. ${ }^{14,19,59,84}$ Cuevas et al. found that $45 \%$ of meningiomas of all grades have hes family bHLH transcription factor 1 (HESI, previously known as induction of hairy and enhancer of Split 1) with overexpression of the Notch receptor or the Jagged ligand, suggesting that there are multiple mechanisms activating the Notch pathway as a critically important genetic alteration in meningioma pathogenesis. ${ }^{16}$ These findings corroborate prior work showing that HES1 is upregulated in meningioma compared with control dural specimens. ${ }^{42}$ Deregulated Notch signaling represents a particularly promising therapeutic target for meningioma treatment.

$M A P K$. Findings from an analysis of 10 human meningiomas indicate that MAPK is constitutively expressed in meningioma cells, and upstream signaling factors of MAPK receptors also act as a mitogen in these meningioma cells. Subsequent inhibition of MAPK activity also blocked upstream mitogenic stimulation of meningioma proliferation, strongly suggesting that MAPK is an important transducer of cell growth. Furthermore, treatment with PD098059, a MAPK inhibitor, produced progressive growth inhibition, correlating with a marked reduction in MAPK phosphorylation and reduced MAPK activity without changing levels of unphosphorylated MAPK (p44) and MAPK (p42) in most of the cell cultures, indicating that MAPK inhibitors may be useful treatments for meningiomas in humans. ${ }^{34}$

The LIF locus encodes a factor that acts upstream of the MAPK cascade. Located at the $22 \mathrm{q}$ chromosomal region, it is an area that is noted for its importance to meningioma pathogenesis. In one study, all of the tumor specimens were hypomethylated at the LIF locus relative to constitutional DNA from the same patients. The researchers found a novel alternatively spliced LIF mRNA, which suggests that the LIF gene may be near a key tumor suppressor locus associated with meningioma development. $^{70}$
Wnt. The Wnt signaling pathway plays a central role in meningioma tumorigenesis. Immunohistochemical studies have previously demonstrated that anaplastic meningiomas frequently lose E-cadherin expression, ${ }^{79}$ which are mediated by beta catenin, ${ }^{46}$ a key Wnt signaling gene. Beta catenin is regulated by the complex of CDK5R 1 and CK5. ${ }^{43}$ When CDK5Rl is upregulated, there seems to be a reduction in beta catenin-regulated cadherin-mediated cell-cell adhesion, ${ }^{79}$ explaining previous immunohistochemical studies that have shown this very reduction. The levels of beta catenin itself seem to increase a function of this regulatory pathway to also act as a transcription factor in the nucleus for multiple genes for the Wnt signaling pathway, furthering its dysregulation. ${ }^{81}$ SFRP1, in the family of frizzled-related proteins, is able to downregulate Wnt signaling by forming an inhibitory complex with frizzled receptors. Its tumor suppressor properties have been noted in many other cancers ${ }^{94}$ and seem to play a role in meninigioma recurrence when it is downregulated, as recurrent meningiomas showed significantly lower mRNA levels than in original meningiomas. ${ }^{69} \mathrm{Hy}-$ permethylation of the SFPRI promoter has been noted to have a similar effect in gliomas, adding to the increasing evidence that epigenetic mechanisms may play a key role in the Wnt signaling pathway.

\section{Histone Acetylation}

Histones and their posttranslational modification system, acetylation, allow for DNA repair and the dynamic regulation of chromatin structure and function. ${ }^{27} \mathrm{~N}$-acetyltransferases bind various compounds to a primary aromatic amine or hydrazine structure and have been linked to various primary carcinomas of diverse epithelial tissues that include bladder cancer and colon cancer. ${ }^{66}$ Olivera et al. ${ }^{103}$ investigated the role of 10 different $\mathrm{N}$-acetyltransferase-2 (NAT2) alleles for meningioma and astrocytoma growth. Individuals carrying rapid acetylation alleles were found to be at increased risk of developing meningioma and astrocytomas compared with healthy volunteers (OR $1.79,95 \%$ CI 1.05-3.05; $\mathrm{p}<0.05)$. It has been hypothesized that the NAT2 polymorphism may have a local effect on brain tumors by activating carcinogens. Indeed, the rapid acetylator genotype has been linked to patients with glioma. ${ }^{87}$ The findings in its role in tumorigenesis have not been conclusive ${ }^{72}$ however, and thus further studies to investigate its role in meningioma growth are necessary.

\section{Angiogenesis}

Epigenetic regulation of angiogenic factors may also play an important, yet undefined role in meningioma oncogenesis. The thrombospondin 1 (THBS1) gene normally inhibits angiogenesis by disrupting the motility of endothelial cells and inducing their apoptosis. ${ }^{29}$ Hypermethylation and subsequent silencing of this gene may therefore promote angiogenesis in tumor cells. ${ }^{67}$ Bello et al. found that $54 \%$ of Grade III meningiomas and $30 \%$ of all cases of meningiomas showed hypermethylation of the $T H B S 1$ gene, ${ }^{5}$ respectively, suggesting that its inactivation could lead to neovascularization of atypical meningiomas and contribute to their progression. 


\section{Other Mechanisms}

Müller et al. found that chromosome 1 alkaline phosphatase (ALPL) was significantly underexpressed in meningioma compared with controls and especially in Grade II/III meningiomas compared with Grade I meningioma. ${ }^{62}$ The exact mechanism of its role in tumorigenesis, however, remains unclear.

\section{Genome-Wide Analysis of Epigenetic Alterations}

In addition to candidate gene studies, genome-wide approaches have the advantage of examining all alterations in an unbiased manner. Earlier this year, we published a study comparing genome-wide methylation patterns in benign, atypical, and malignant meningiomas. ${ }^{26}$ To our knowledge, this is the first study to explore genome-scale DNA methylation in malignant, atypical, and benign meningiomas. Additionally, unlike most previous cancer genetics studies that compare DNA methylation patterns between tumor and normal tissue, our goal was to investigate whether benign and malignant tumors differ in DNA methylation patterns and whether these differences have biological and clinical significance. Compared with the benign tumors, the atypical and malignant meningiomas demonstrate increased global DNA hypomethylation. Interestingly, while hierarchical clustering analysis readily separates malignant from atypical and benign tumors, it cannot separate atypical and benign tumors, implicating that DNA methylation patterns may serve as diagnostic biomarkers for malignancy. Additionally, we investigated the correlation between methylation and gene expression. Most genes with hypermethylated $\mathrm{CpG}$ islands in promoter regions are suppressed in both malignant and benign meningiomas, suggesting the switching of gene silencing machinery from polycomb repressor complex (PRC) binding to DNA methylation in malignant meningiomas. One exception is the MAL2 gene, which has high expression in levels in benign meningiomas but low expression in malignant tumors. MAL2 has hypermethylation at a $\mathrm{CpG}$ island in its promoter region in malignant meningiomas, therefore representing de novo gene silencing induced by DNA methylation.

In addition to methylation, alterations of histone modification and higher-order chromosomal structure represent additional epigenetic mechanisms that may regulate gene expression and function. Because of the availability of high-throughput sequencing, these studies have now become increasingly popular in molecular genetics studies. For example, the ChIP-sequencing (ChIP-seq) technique, which combines chromatin immune-precipitation with next-generation sequencing, can be used to examine histone modification patterns given antibodies for the specific modifications. Similarly, 3C, 4C, 5C, Hi-C and ChIA-PET techniques, ${ }^{18,20,82}$ were specifically developed for interrogating higher-order chromosomal structures between regulatory elements and target genes that may be located far away (even in different chromosomes). These techniques were becoming increasingly popular in molecular genetics studies of cancer. However, to our knowledge, these types of studies have not yet been reported on meningiomas. It is expected that identification of additional epigenetic changes, such as histone modification and higher-order chromosomal structure, may allow for a more thorough understanding of tumorigenesis and enable future individualized treatment strategies for meningiomas.

\section{Discussion}

The literature pertaining to epigenetic regulation of meningiomas demonstrates that progressively more methylated loci, in general, are associated with increasing tumor grades. This is likely explained by widespread silencing of tumor-suppressor genes and pathways. This finding is also consistent with findings of previous studies showing that mutations within the genes themselves coincide with increasing tumor grade. ${ }^{31,52}$ In addition, there was a trend for Grade I and II meningiomas to have more hypermethylated loci than genetically mutated loci, highlighting the role that methylation plays in early meningioma tumorigenesis, vis-à-vis somatic mutations.

Aberrant DNA methylation is thought to silence genes and reduce expression by blocking transcriptional machinery access to DNA. ${ }^{35}$ This suggests that DNA methylation is potentially acquired before phenotypical changes and that aberrant methylation may be a harbinger of malignant transformation and recurrence.

\section{Types of Epigenetic Alteration}

Epigenetic alterations in the genome often occur in the early stages of tumorigenesis ${ }^{35}$ through aberrant DNA methylation ${ }^{45}$-in particular, $\mathrm{CpG}$ island hypermethylation of promoter regions that results in tumor-suppressor gene silencing and tumorigenesis. ${ }^{6,35}$ Normally, many genes have promoter regions that are densely populated with $\mathrm{CpG}$ dinucleotides, termed $\mathrm{CpG}$ islands, which are maintained in an unmethylated state. Subsequent hypermethylation of these $\mathrm{CpG}$ islands at the promoter region has been shown to silence and inactivate gene expression downstream. If the gene is a growth inhibitor or DNA repair enzyme, for example, then growth goes unchecked, often leading to tumorigenesis. ${ }^{33}$ In recent years, it has been shown that DNA methylation at non-CpG island sites may play as important a role in modulating gene expression as methylation occurring at promoter $\mathrm{CpG}$ island sites.

\section{Gene Methylation Detection Methods}

In general, researchers use 2 approaches to detect aberrant epigenetic modifications: single-gene (targeted) approaches and genome-wide assessments. The methylation status of single candidate genes can be screened for abnormal epigenetic modifications if they have been previously implicated or prioritized as playing a role in tumorigenesis or transformation, using techniques such as polymerase chain reaction or MethyLight. The singlegene approach, however, is limited, as it only surveys a fraction of the possible modifications to that gene, while also being unable to study the role of additional genes that may contribute to oncogenesis or anaplasia. ${ }^{77}$ Largerscale methods for detecting epigenetic involvement in 


\section{Epigenetic and gene expression alterations in meningioma}

meningiomas involve restriction landmark genome scanning (RLGS), a two-dimensional gel-based method for assessing methylation status in thousands of $\mathrm{CpG}$ islands simultaneously. ${ }^{32}$ Over the past decade, next-generation high-throughput techniques for assessing methylation status across the entire genome have become increasingly used to study meningiomas. ${ }^{26}$

\section{Distinction Between Genetic and Epigenetic Mutation Targets}

The most clearly established genetic mutation for meningiomas is inactivation of the neurofibromin 2 (NF2) gene located on $22 \mathrm{q}$, with the associated loss of its merlin protein expression. ${ }^{68,73}$ NF2 mutations have been detected in more than $50 \%$ of all sporadic meningiomas in all pathological grades, clearly showing that mutation of $N F 2$ plays an important early role in meningioma development. ${ }^{89,93}$ It should be surprising to note, then, that $N F 2$ is not a frequent target of epigenetic modification. ${ }^{25}$ An analysis of $40 \mathrm{CpG}$ sites within $750 \mathrm{bp}$ of the promoter regions of $N F 2$ showed no methylation of these regions, ${ }^{30}$ and the NF2 gene itself was methylated in only 1 of 21 tumors in a separate study. ${ }^{91}$ Other mechanisms involved in loss of function of $N F 2$, such as chromosomal deletions and primary mutations, are more likely to affect $N F 2$ expression than are epigenetic alterations.

Other important genes that have been previously noted as significant in meningioma development but not found as targets of epigenetic target modification include ADAM23, ${ }^{13}$ MGMT, CDKN2A, CDKN2B,CDKN2C, $C D K N 2 D$, and $R B 1(R B) .{ }^{73}$ Esteller al. previously reported promoter hypermethylation of $M G M T$ in various neoplasms throughout the body, ${ }^{23}$ with rates ranging from $21 \%$ in lung cancers to $34 \%$ of all brain tumors. In meningiomas, however, only $6 \%$ of $M G M T$ promoters were hypermethylated in 1 group of 48 meningioma cases ${ }^{49}$ and a separate group of 36 meningioma cases. ${ }^{17}$ MGMT promoter hypermethylation was also not correlated with grade of the neoplasm. ${ }^{37,94}$

Our results show that epigenetic and transcriptomic alterations in various tumor suppressors are likely to play an active role in meningioma development. We noted, however, that this mechanism of tumor progression did not seem to develop for RB1. CDKN2A (p16[INK4A]) and $C D K N 2 B$ (p15[INK4B]) are genes on the 9p21 locus that regulate the transition from $\mathrm{G}_{1} / \mathrm{S}$-phase checkpoint and interact with and $R B 1 . .^{5}$ Loss of $C D K N 2 A, C D K N 2 B$, or $R B I$ activity through mutation or methylation would, in theory, disrupt the growth-regulatory pathway and allow unrestrained cell proliferation. ${ }^{49}$ However, the low frequency of methylation of $C D K N 2 B(p 15[I N K 4 B]),{ }^{8}$ $C D K N 2 A(p 16[I N K 4 A])^{8,49,88}$ along with $R B 1$ genes suggests that methylation of these growth control genes does not play a major role in the development of a majority of brain tumors. ${ }^{97}$ CDKN2C (p18[INK4C]) CDK inhibitors do not seem to have any role in meningioma progression as well, even though they serve a similar cell cycle regulatory function. ${ }^{8}$ A subset of 67 meningiomas showed only a single tumor with any alterations at the $C D K N 2 C$ locus. This lack of epigenetic modification applied to $C D K N 2 D$ at $19 \mathrm{q} 13^{78}$ as well.
Accordingly, Boström et al. proposed that regulation of $C D K N$ transcription in meningiomas might be influenced by as yet unknown mechanisms in addition to hypermethylation. This may explain why genetic mechanisms but not epigenetic mechanisms are crucial in meningioma progression for the $R B$ pathway. ${ }^{8}$

\section{Future Directions}

The divergence between genetic and epigenetic manifestations in meningioma progression clearly illustrates the challenge that expression profiles attempt to portray in a phenotypically heterogenous neoplasm. It will be important to investigate expression profiles of more genes in a larger series of tumors with clinical follow-up data to ensure that genes are correlated to grade and clinical outcome as well.

\section{Conclusions}

We present here a comprehensive review of the epigenetic alterations of genes and corresponding changes in gene expression that may lead to meningioma development, progression, and recurrence. Additional analysis and discovery of other genetic and epigenetic mechanisms involved in meningioma pathogenesis is needed to fully understand this tumor's biology. Future research into potential primary or adjuvant treatments with demethylating and deacetylating agents will be important in elucidating their potential role in the management of meningiomas.

\section{Disclosure}

The authors report no conflict of interest concerning the materials or methods used in this study or the findings specified in this paper.

Author contributions to the study and manuscript preparation include the following. Conception and design: He, Pham, Zada, Mack. Acquisition of data: He, Pham, Pease. Analysis and interpretation of data: He, Pham, Pease. Drafting the article: He, Pham, Pease. Critically revising the article: He, Pham, Giannotta, Wang, Zada, Mack. Reviewed submitted version of manuscript: He, Pham, Giannotta, Wang, Zada, Mack. Approved the final version of the manuscript on behalf of all authors: He. Study supervision: Giannotta, Zada, Mack.

\section{References}

1. Ahomadegbe JC, Tourpin S, Kaghad M, Zelek L, Vayssade $\mathrm{M}$, Mathieu MC, et al: Loss of heterozygosity, allele silencing and decreased expression of $\mathrm{p} 73$ gene in breast cancers: prevalence of alterations in inflammatory breast cancers. Oncogene 19:5413-5418, 2000

2. Al-Mefty O, Kadri PA, Pravdenkova S, Sawyer JR, Stangeby $\mathrm{C}$, Husain M: Malignant progression in meningioma: documentation of a series and analysis of cytogenetic findings. $\mathbf{J}$ Neurosurg 101:210-218, 2004

3. Anand-Apte B, Bao L, Smith R, Iwata K, Olsen BR, Zetter $\mathrm{B}$, et al: A review of tissue inhibitor of metalloproteinases-3 (TIMP-3) and experimental analysis of its effect on primary tumor growth. Biochem Cell Biol 74:853-862, 1996

4. Barski D, Wolter M, Reifenberger G, Riemenschneider MJ: Hypermethylation and transcriptional downregulation of the TIMP3 gene is associated with allelic loss on 22q12.3 and malignancy in meningiomas. Brain Pathol 20:623-631, 2010 


\section{S. He et al.}

5. Bello MJ, Amiñoso C, Lopez-Marin I, Arjona D, GonzalezGomez P, Alonso ME, et al: DNA methylation of multiple promoter-associated $\mathrm{CpG}$ islands in meningiomas: relationship with the allelic status at $1 \mathrm{p}$ and 22q. Acta Neuropathol 108:413-421, 2004

6. Berman BP, Weisenberger DJ, Aman JF, Hinoue T, Ramjan Z, Liu Y, et al: Regions of focal DNA hypermethylation and long-range hypomethylation in colorectal cancer coincide with nuclear lamina-associated domains. Nat Genet 44:4046, 2012

7. Bian J, Wang Y, Smith MR, Kim H, Jacobs C, Jackman J, et al: Suppression of in vivo tumor growth and induction of suspension cell death by tissue inhibitor of metalloproteinases (TIMP)-3. Carcinogenesis 17:1805-1811, 1996

8. Boström J, Meyer-Puttlitz B, Wolter M, Blaschke B, Weber RG, Lichter P, et al: Alterations of the tumor suppressor genes CDKN2A (p16(INK4a)), p14(ARF), CDKN2B (p15(INK4b)), and CDKN2C (p18(INK4c)) in atypical and anaplastic meningiomas. Am J Pathol 159:661-669, 2001

9. Cahill KS, Claus EB: Treatment and survival of patients with nonmalignant intracranial meningioma: results from the Surveillance, Epidemiology, and End Results Program of the National Cancer Institute. Clinical article. J Neurosurg 115: 259-267, 2011

10. Chung JH, Lee HJ, Kim BH, Cho NY, Kang GH: DNA methylation profile during multistage progression of pulmonary adenocarcinomas. Virchows Arch 459:201-211, 2011

11. Cicha I, Goppelt-Struebe M: Connective tissue growth factor: context-dependent functions and mechanisms of regulation. Biofactors 35:200-208, 2009

12. Conover CA, Bale LK, Durham SK, Powell DR: Insulin-like growth factor (IGF) binding protein-3 potentiation of IGF action is mediated through the phosphatidylinositol-3-kinase pathway and is associated with alteration in protein kinase B/ AKT sensitivity. Endocrinology 141:3098-3103, 2000

13. Costa FF, Colin C, Shinjo SM, Zanata SM, Marie SK, Sogayar $\mathrm{MC}$, et al: ADAM23 methylation and expression analysis in brain tumors. Neurosci Lett 380:260-264, 2005

14. Crea F, Danesi R, Farrar WL: Cancer stem cell epigenetics and chemoresistance. Epigenomics 1:63-79, 2009

15. Cubeddu L, Joseph S, Richard DJ, Matthews JM: Contribution of DEAF1 structural domains to the interaction with the breast cancer oncogene LMO4. PLoS ONE 7:e39218, 2012

16. Cuevas IC, Slocum AL, Jun P, Costello JF, Bollen AW, Riggins GJ, et al: Meningioma transcript profiles reveal deregulated Notch signaling pathway. Cancer Res 65:5070-5075, 2005

17. de Robles P, McIntyre J, Kalra S, Roldán G, Cairncross G, Forsyth P, et al: Methylation status of MGMT gene promoter in meningiomas. Cancer Genet Cytogenet 187:25-27, 2008

18. de Wit E, de Laat W: A decade of 3C technologies: insights into nuclear organization. Genes Dev 26:11-24, 2012

19. Deb M, Sengupta D, Patra SK: Integrin-epigenetics: a system with imperative impact on cancer. Cancer Metastasis Rev 31:221-234, 2012

20. Dekker J, Marti-Renom MA, Mirny LA: Exploring the threedimensional organization of genomes: interpreting chromatin interaction data. Nat Rev Genet 14:390-403, 2013

21. Di Vinci A, Brigati C, Casciano I, Banelli B, Borzì L, Forlani A, et al: HOXA7, 9, and 10 are methylation targets associated with aggressive behavior in meningiomas. Transl Res 160:355-362, 2012

22. Durand A, Labrousse F, Jouvet A, Bauchet L, Kalamaridès M, Menei P, et al: WHO grade II and III meningiomas: a study of prognostic factors. J Neurooncol 95:367-375, 2009

23. Esteller M, Corn PG, Baylin SB, Herman JG: A gene hypermethylation profile of human cancer. Cancer Res 61:32253229, 2001

24. Fan Y, Nikitina T, Zhao J, Fleury TJ, Bhattacharyya R, Bouhassira EE, et al: Histone $\mathrm{H} 1$ depletion in mammals alters global chromatin structure but causes specific changes in gene regulation. Cell 123:1199-1212, 2005

25. Fontaine B, Rouleau GA, Seizinger B, Jewell AF, Hanson MP, Martuza RL, et al: Equal parental origin of chromosome 22 losses in human sporadic meningioma: no evidence for genomic imprinting. Am J Hum Genet 47:823-827, 1990

26. Gao F, Shi L, Russin J, Zeng L, Chang X, He S, et al: DNA methylation in the malignant transformation of meningiomas. PLoS ONE 8:e54114, 2013

27. Gong F, Miller KM: Mammalian DNA repair: HATs and HDACs make their mark through histone acetylation. Mutat Res [epub ahead of print], 2013

28. Grady WM: Genomic instability and colon cancer. Cancer Metastasis Rev 23:11-27, 2004

29. Guha A, Vasconcelos M, Cai Y, Yoneda M, Hinds A, Qian J, et al: Neuroepithelial body microenvironment is a niche for a distinct subset of Clara-like precursors in the developing airways. Proc Natl Acad Sci U S A 109:12592-12597, 2012

30. Hansson CM, Buckley PG, Grigelioniene G, Piotrowski A, Hellström AR, Mantripragada K, et al: Comprehensive genetic and epigenetic analysis of sporadic meningioma for macromutations on $22 \mathrm{q}$ and micro-mutations within the NF2 locus. BMC Genomics 8: 16, 2007

31. Harada T, Irving RM, Xuereb JH, Barton DE, Hardy DG, Moffat DA, et al: Molecular genetic investigation of the neurofibromatosis type 2 tumor suppressor gene in sporadic meningioma. J Neurosurg 84:847-851, 1996

32. Hatada I, Hayashizaki Y, Hirotsune S, Komatsubara H, Mukai T: A genomic scanning method for higher organisms using restriction sites as landmarks. Proc Natl Acad Sci U S A 88:9523-9527, 1991

33. Helleman J, van Staveren IL, Dinjens WN, van Kuijk PF, Ritstier K, Ewing PC, et al: Mismatch repair and treatment resistance in ovarian cancer. BMC Cancer 6:201, 2006

34. Johnson MD, Woodard A, Kim P, Frexes-Steed M: Evidence for mitogen-associated protein kinase activation and transduction of mitogenic signals by platelet-derived growth factor in human meningioma cells. J Neurosurg 94:293-300, 2001

35. Jones PA, Baylin SB: The epigenomics of cancer. Cell 128: 683-692, 2007

36. Ju HX, An B, Okamoto Y, Shinjo K, Kanemitsu Y, Komori $\mathrm{K}$, et al: Distinct profiles of epigenetic evolution between colorectal cancers with and without metastasis. Am J Pathol 178:1835-1846, 2011

37. Jun P, Hong C, Lal A, Wong JM, McDermott MW, Bollen $\mathrm{AW}$, et al: Epigenetic silencing of the kinase tumor suppressor WNK2 is tumor-type and tumor-grade specific. Neuro Oncol 11:414-422, 2009

38. Jung HW, Yoo H, Paek SH, Choi KS: Long-term outcome and growth rate of subtotally resected petroclival meningiomas: experience with 38 cases. Neurosurgery 46:567-575, 2000

39. Kaghad M, Bonnet H, Yang A, Creancier L, Biscan JC, Valent A, et al: Monoallelically expressed gene related to p53 at $1 \mathrm{p} 36$, a region frequently deleted in neuroblastoma and other human cancers. Cell 90:809-819, 1997

40. Kandenwein JA, Park-Simon TW, Schramm J, Simon M: uPA/ PAI-1 expression and uPA promoter methylation in meningiomas. J Neurooncol 103:533-539, 2011

41. Katoh Y, Katoh M: Identification and characterization of CDC50A, CDC50B and CDC50C genes in silico. Oncol Rep 12:939-943, 2004

42. Keller A, Ludwig N, Backes C, Romeike BF, Comtesse N, Henn W, et al: Genome wide expression profiling identifies specific deregulated pathways in meningioma. Int $\mathbf{J}$ Cancer 124:346-351, 2009

43. Kesavapany S, Lau KF, McLoughlin DM, Brownlees J, Ackerley S, Leigh PN, et al: p35/cdk5 binds and phosphorylates beta-catenin and regulates beta-catenin/presenilin-1 interaction. Eur J Neurosci 13:241-247, 2001

44. Kim HE, Kim DG, Lee KJ, Son JG, Song MY, Park YM, et al: 


\section{Epigenetic and gene expression alterations in meningioma}

Frequent amplification of CENPF, GMNN and CDK13 genes in hepatocellular carcinomas. PLoS ONE 7:e43223, 2012

45. Kishida Y, Natsume A, Kondo Y, Takeuchi I, An B, Okamoto $\mathrm{Y}$, et al: Epigenetic subclassification of meningiomas based on genome-wide DNA methylation analyses. Carcinogenesis 33:436-441, 2012

46. Kwon YT, Gupta A, Zhou Y, Nikolic M, Tsai LH: Regulation of N-cadherin-mediated adhesion by the p35-Cdk5 kinase. Curr Biol 10:363-372, 2000

47. Laird PW: The power and the promise of DNA methylation markers. Nat Rev Cancer 3:253-266, 2003

48. Lamszus K: Meningioma pathology, genetics, and biology. J Neuropathol Exp Neurol 63:275-286, 2004

49. Liu Y, Pang JC, Dong S, Mao B, Poon WS, Ng HK: Aberrant $\mathrm{CpG}$ island hypermethylation profile is associated with atypical and anaplastic meningiomas. Hum Pathol 36:416-425, 2005

50. Louis DN, Ohgaki H, Wiestler OD, Cavenee WK, Burger PC, Jouvet A, et al: The 2007 WHO classification of tumours of the central nervous system. Acta Neuropathol 114:97-109, 2007

51. Louis DN, Pomeroy SL, Cairncross JG: Focus on central nervous system neoplasia. Cancer Cell 1:125-128, 2002

52. Louis DN, Ramesh V, Gusella JF: Neuropathology and molecular genetics of neurofibromatosis 2 and related tumors. Brain Pathol 5:163-172, 1995

53. Lu Z, Lam KS, Wang N, Xu X, Cortes M, Andersen B: LMO4 can interact with Smad proteins and modulate transforming growth factor-beta signaling in epithelial cells. Oncogene 25: 2920-2930, 2006

54. Lusis EA, Watson MA, Chicoine MR, Lyman M, Roerig P, Reifenberger G, et al: Integrative genomic analysis identifies NDRG2 as a candidate tumor suppressor gene frequently inactivated in clinically aggressive meningioma. Cancer Res 65: 7121-7126, 2005

55. Maillo A, Orfao A, Espinosa AB, Sayagués JM, Merino M, Sousa P, et al: Early recurrences in histologically benign/ grade I meningiomas are associated with large tumors and coexistence of monosomy 14 and $\operatorname{del}(1 \mathrm{p} 36)$ in the ancestral tumor cell clone. Neuro Oncol 9:438-446, 2007

56. Matsumoto Y: Molecular mechanism of PCNA-dependent base excision repair. Prog Nucleic Acid Res Mol Biol 68:129-138, 2001

57. McTavish N, Copeland LA, Saville MK, Perkins ND, Spruce BA: Proenkephalin assists stress-activated apoptosis through transcriptional repression of NF-kappaB- and p53-regulated gene targets. Cell Death Differ 14:1700-1710, 2007

58. Melino G, De Laurenzi V, Vousden KH: p73: Friend or foe in tumorigenesis. Nat Rev Cancer 2:605-615, 2002

59. Merdes G, Paro R: About combs, notches, and tumors: epigenetics meets signaling. Dev Cell 17:440-442, 2009

60. Moniz S, Veríssimo F, Matos P, Brazão R, Silva E, Kotelevets L, et al: Protein kinase WNK2 inhibits cell proliferation by negatively modulating the activation of MEK1/ERK1/2. Oncogene 26:6071-6081, 2007

61. Montañez-Wiscovich ME, Shelton MD, Seachrist DD, Lozada KL, Johnson E, Miedler JD, et al: Aberrant expression of LMO4 induces centrosome amplification and mitotic spindle abnormalities in breast cancer cells. J Pathol 222:271-281, 2010

62. Müller P, Henn W, Niedermayer I, Ketter R, Feiden W, Steudel WI, et al: Deletion of chromosome 1p and loss of expression of alkaline phosphatase indicate progression of meningiomas. Clin Cancer Res 5:3569-3577, 1999

63. Murphy NC, Scarlett CJ, Kench JG, Sum EY, Segara D, Colvin EK, et al: Expression of LMO4 and outcome in pancreatic ductal adenocarcinoma. Br J Cancer 98:537-541, 2008

64. Nakane Y, Natsume A, Wakabayashi T, Oi S, Ito M, Inao S, et al: Malignant transformation-related genes in meningiomas: allelic loss on 1p36 and methylation status of p73 and RASSF1A. J Neurosurg 107:398-404, 2007
65. Nordqvist AC, Peyrard M, Pettersson H, Mathiesen T, Collins VP, Dumanski JP, et al: A high ratio of insulin-like growth factor II/insulin-like growth factor binding protein 2 messenger RNA as a marker for anaplasia in meningiomas. Cancer Res 57:2611-2614, 1997

66. Pande JN, Pande A, Singh SP: Acetylator status, drug metabolism and disease. Natl Med J India 16:24-26, 2003

67. Panetti TS, Chen H, Misenheimer TM, Getzler SB, Mosher DF: Endothelial cell mitogenesis induced by LPA: inhibition by thrombospondin-1 and thrombospondin-2. J Lab Clin Med 129:208-216, 1997

68. Papi L, De Vitis LR, Vitelli F, Ammannati F, Mennonna P, Montali E, et al: Somatic mutations in the neurofibromatosis type 2 gene in sporadic meningiomas. Hum Genet 95:347351,1995

69. Pérez-Magán E, Rodríguez de Lope A, Ribalta T, Ruano Y, Campos-Martín Y, Pérez-Bautista G, et al: Differential expression profiling analyses identifies downregulation of $1 \mathrm{p}, 6 \mathrm{q}$, and $14 \mathrm{q}$ genes and overexpression of $6 \mathrm{p}$ histone cluster 1 genes as markers of recurrence in meningiomas. Neuro Oncol 12:12781290,2010

70. Pergolizzi RG, Erster SH: Analysis of chromosome 22 loci in meningioma. Alterations in the leukemia inhibitory factor (LIF) locus. Mol Chem Neuropathol 21:189-217, 1994

71. Perry A: Pathology of low-grade gliomas: an update of emerging concepts. Neuro Oncol 5:168-178, 2003

72. Peters ES, Kelsey KT, Wiencke JK, Park S, Chen P, Miike $R$, et al: NAT2 and NQO1 polymorphisms are not associated with adult glioma. Cancer Epidemiol Biomarkers Prev 10:151-152, 2001

73. Pham MH, Zada G, Mosich GM, Chen TC, Giannotta SL, Wang K, et al: Molecular genetics of meningiomas: a systematic review of the current literature and potential basis for future treatment paradigms. Neurosurg Focus 30(5):E7, 2011

74. Porter KR, McCarthy BJ, Freels S, Kim Y, Davis FG: Prevalence estimates for primary brain tumors in the United States by age, gender, behavior, and histology. Neuro Oncol 12:520527,2010

75. Qu X, Zhai Y, Wei H, Zhang C, Xing G, Yu Y, et al: Characterization and expression of three novel differentiation-related genes belong to the human NDRG gene family. Mol Cell Biochem 229:35-44, 2002

76. Rauch T, Wang Z, Zhang X, Zhong X, Wu X, Lau SK, et al: Homeobox gene methylation in lung cancer studied by genome-wide analysis with a microarray-based methylated $\mathrm{CpG}$ island recovery assay. Proc Natl Acad Sci U S A 104:55275532,2007

77. Rollins RA, Haghighi F, Edwards JR, Das R, Zhang MQ, Ju J, et al: Large-scale structure of genomic methylation patterns. Genome Res 16:157-163, 2006

78. Ruas M, Peters G: The p16INK4a/CDKN2A tumor suppressor and its relatives. Biochim Biophys Acta 1378:F115-F177, 1998

79. Schwechheimer K, Zhou L, Birchmeier W: E-Cadherin in human brain tumours: loss of immunoreactivity in malignant meningiomas. Virchows Arch 432:163-167, 1998

80. Shitani M, Sasaki S, Akutsu N, Takagi H, Suzuki H, Nojima $\mathrm{M}$, et al: Genome-wide analysis of DNA methylation identifies novel cancer-related genes in hepatocellular carcinoma. Tumour Biol 33:1307-1317, 2012

81. Shtutman M, Zhurinsky J, Simcha I, Albanese C, D'Amico $\mathrm{M}$, Pestell R, et al: The cyclin D1 gene is a target of the betacatenin/LEF-1 pathway. Proc Natl Acad Sci U S A 96:55225527,1999

82. Smallwood A, Ren B: Genome organization and long-range regulation of gene expression by enhancers. Curr Opin Cell Biol 25:387-394, 2013

83. Soshnikova N, Duboule D: Epigenetic regulation of Hox gene activation: the waltz of methyls. Bioessays 30:199-202, 2008

84. Strizzi L, Hardy KM, Seftor EA, Costa FF, Kirschmann DA, 
Seftor RE, et al: Development and cancer: at the crossroads of Nodal and Notch signaling. Cancer Res 69:7131-7134, 2009

85. Ting DT, Lipson D, Paul S, Brannigan BW, Akhavanfard S, Coffman EJ, et al: Aberrant overexpression of satellite repeats in pancreatic and other epithelial cancers. Science 331:593596,2011

86. Toralová T, Susor A, Nemcová L, Kepková K, Kanka J: Silencing CENPF in bovine preimplantation embryo induces arrest at 8-cell stage. Reproduction 138:783-791, 2009

87. Trizna Z, de Andrade M, Kyritsis AP, Briggs K, Levin VA, Bruner JM, et al: Genetic polymorphisms in glutathione Stransferase mu and theta, N-acetyltransferase, and CYP1A1 and risk of gliomas. Cancer Epidemiol Biomarkers Prev 7:553-555, 1998

88. Tse JY, Ng HK, Lo KW, Chong EY, Lam PY, Ng EK, et al: Analysis of cell cycle regulators: p16INK4A, pRb, and CDK4 in low- and high-grade meningiomas. Hum Pathol 29:12001207,1998

89. Ueki K, Wen-Bin C, Narita Y, Asai A, Kirino T: Tight association of loss of merlin expression with loss of heterozygosity at chromosome $22 \mathrm{q}$ in sporadic meningiomas. Cancer Res 59:5995-5998, 1999

90. Ueki T, Toyota M, Skinner H, Walter KM, Yeo CJ, Issa JP, et al: Identification and characterization of differentially methylated $\mathrm{CpG}$ islands in pancreatic carcinoma. Cancer Res 61: 8540-8546, 2001

91. van Tilborg AA, Morolli B, Giphart-Gassler M, de Vries A, van Geenen DA, Lurkin I, et al: Lack of genetic and epigenetic changes in meningiomas without NF2 loss. J Pathol 208:564-573, 2006

92. Watson MA, Gutmann DH, Peterson K, Chicoine MR, Kleinschmidt-DeMasters BK, Brown HG, et al: Molecular characterization of human meningiomas by gene expression profiling using high-density oligonucleotide microarrays. Am J Pathol 161:665-672, 2002

93. Wellenreuther R, Kraus JA, Lenartz D, Menon AG, Schramm $\mathrm{J}$, Louis DN, et al: Analysis of the neurofibromatosis 2 gene reveals molecular variants of meningioma. Am J Pathol 146: 827-832, 1995

94. Wrobel G, Roerig P, Kokocinski F, Neben K, Hahn M, Reifenberger G, et al: Microarray-based gene expression profiling of benign, atypical and anaplastic meningiomas identifies novel genes associated with meningioma progression. Int J Cancer 114:249-256, 2005
95. Wu Q, Lothe RA, Ahlquist T, Silins I, Tropé CG, Micci F, et al: DNA methylation profiling of ovarian carcinomas and their in vitro models identifies HOXA9, HOXB5, SCGB3A1, and CRABP1 as novel targets. Mol Cancer 6:45, 2007

96. Yamasawa K, Nio Y, Dong M, Yamaguchi K, Itakura M: Clinicopathological significance of abnormalities in Gadd45 expression and its relationship to p53 in human pancreatic cancer. Clin Cancer Res 8:2563-2569, 2002

97. Yin D, Xie D, Hofmann WK, Miller CW, Black KL, Koeffler HP: Methylation, expression, and mutation analysis of the cell cycle control genes in human brain tumors. Oncogene 21: 8372-8378, 2002

98. Zhang X, Gejman R, Mahta A, Zhong Y, Rice KA, Zhou Y, et al: Maternally expressed gene 3, an imprinted noncoding RNA gene, is associated with meningioma pathogenesis and progression. Cancer Res 70:2350-2358, 2010

99. Zhang Y, Xiong Y, Yarbrough WG: ARF promotes MDM2 degradation and stabilizes p53: ARF-INK4a locus deletion impairs both the $\mathrm{Rb}$ and $\mathrm{p} 53$ tumor suppression pathways. Cell 92:725-734, 1998

100. Zhou Y, Zhong Y, Wang Y, Zhang X, Batista DL, Gejman $\mathrm{R}$, et al: Activation of p53 by MEG3 non-coding RNA. J Biol Chem 282:24731-24742, 2007

101. Ziaja-Sołtys M, Rzymowska J: The determination of changes in the expression of genes for selected specific transcriptional factors in in vitro ductal breast cancer cells under the influence of paclitaxel. Cell Mol Biol Lett 16:610-624, 2011

102. Zupančič D, Zakrajšek M, Zhou G, Romih R: Expression and localization of four uroplakins in urothelial preneoplastic lesions. Histochem Cell Biol 136:491-500, 2011

103. Olivera M, Martínez C, Molina JA, Alonso-Navarro H, Jiménez-Jiménez FJ, García-Martín E: Increased frequency of rapid acetylator genotypes in patients with brain astrocytoma and meningioma. Acta Neurol Scand 113:322-326, 2006

Manuscript submitted August 15, 2013.

Accepted October 4, 2013.

Please include this information when citing this paper: DOI: 10.3171/2013.10.FOCUS13360.

Address correspondence to: Shuhan He, B.S., LAC+USC Medical Center, 1200 N. State St., Ste. 3300, Los Angeles, CA 90033. email: shuhan.he1@gmail.com. 